\title{
Produção de zeólita analcima a partir de caulim amazônico
}

\section{(Analcime zeolite production from amazon kaolin)}

\author{
C. G. Moraes ${ }^{1}$, E. C. Rodrigues ${ }^{1}$, R. S. Angélica ${ }^{2}$, E. N. Macêdo ${ }^{1}$, R. F. Neves ${ }^{1}$ \\ ${ }^{1}$ Programa de Pós-Graduação em Engenharia Química (PPEQ /ITEC) \\ ${ }^{2}$ Programa de Pós-Graduação em Geologia e Geoquímica (PPGG/IG) \\ Universidade Federal do Pará, R. Augusto Corrêa 01, Guamá, Belém, PA 66075-110 \\ crisqi02@gmail.com
}

\begin{abstract}
Resumo
Na região norte do Brasil são encontradas grandes reservas minerais, as quais tem sido exploradas nas últimas décadas gerando normalmente grande volume de rejeito para o meio ambiente. No caso específico do caulim, o principal produto exportado é para cobertura de papel (commodity) que apresenta baixo valor agregado. Sua produção, também gera um rejeito volumoso composto essencialmente de caulinita, de elevada pureza, porem fora de especificação para cobertura de papel que é descartado e ou utilizado em outras aplicações menos nobre. Como as zeólitas são materiais mais nobres e apresentam na sua estrutura cristalina sílica e alumina este trabalho teve como um dos objetivos o desenvolvimento de processo de produção da zeólita analcima a partir de um rejeito de caulim menos nobre, diatomito e solução de hidróxido de sódio. Por outo lado, os métodos descritos na literatura para obtenção de zeólitas são desenvolvidos em meio alcalino e utilizam normalmente um excesso de hidróxido de sódio no meio reacional ocasionado problema econômico e ambiental. Assim este trabalho descreve o processo de síntese da zeólita analcima semi-contínuo, no qual o excesso de hidróxido utilizado foi recuperado e reutilizado em um novo ciclo de processo. O processo foi desenvolvido em cinco ciclos consecutivos em autoclave através da reação de caulim calcinado, diatomito como fonte de sílica adicional, solução aquosa de hidróxido de sódio fresco e solução de hidróxido de sódio reciclada. A reação do processo foi desenvolvida a $210^{\circ} \mathrm{C}$ por $24 \mathrm{~h}$. O produto obtido no final de cada ciclo foi a zeólita analcima caracterizada por fluorescência de raios X, difração de raios, análise termogravimétrica-térmica diferencial, e microscopia eletrônica de varredura. O processo de produção de analcima apresentou elevado rendimento e o reaproveitamento do hidróxido de sódio por meio de reciclo mostrou-se tecnicamente viável.
\end{abstract}

Palavras-chave: zeólita, analcima, caulim, síntese.

\begin{abstract}
In the north of Brazil large mineral reserves are found, which have been exploited in recent decades typically generating large volumes of waste to the environment. In the specific case of the kaolin is the main product exported is for paper coating (commodity) with low value. Its production also generates a massive waste composed mainly of high purity kaolinite, but with no specification to cover paper, being discarded or used in other less noble application. As zeolites are more noble materials and present silica and alumina, one of the goals of this work was the development of the production process of the zeolite analcime from kaolin waste, diatomite and sodium hydroxide solution. In the other hand, the methods described for obtaining zeolites are developed in an alkaline medium, typically using an excess of sodium hydroxide in the reaction, causing environmental and economic problems. The synthesis process of zeolite analcime semi-continuous is described, using excess of sodium hydroxide to be recovered and reused in a new process cycle. The process consisted in five consecutive cycles in an autoclave by reaction of calcined kaolin, diatomaceous earth as a source of additional silica, aqueous solution of sodium hydroxide, and fresh sodium hydroxide solution, and recycled. The reaction process was developed at $210^{\circ} \mathrm{C}$ for $24 \mathrm{~h}$. The product obtained at the end of each cycle was analcime zeolite characterized by $X R F, X R D, D T A$ / TG, SEM. The production process of analcime showed high yield and reuse of sodium hydroxide through recycle to be technically feasible.
\end{abstract}

Keywords: zeolite, analcime, kaolin, synthesis.

\section{INTRODUÇÃO}

O Brasil é o sexto maior produtor mundial de caulim, produzindo aproximadamente 2,8 milhões de toneladas em 2008 , ou cerca de $6 \%$ da produção mundial, de 44,7 milhões de toneladas. Segundo o Anuário Mineral Brasileiro DNPM 
[1] as reservas brasileiras medidas e indicadas alcançam 7,2 milhões de toneladas, e as empresas de beneficiamento de caulim, que atuam quase que exclusivamente na produção de caulim para cobertura de papel estão localizadas no estado do Pará que são a Imerys Rio Capim Caulim S/A, Caulim da Amazônia S/A(CADAM/Vale) e Pará Pigmentos S/A(PPSA/ Vale). O caulim é uma argila constituída essencialmente pelo argilomineral caulinita, com granulometria fina, normalmente com baixo teor de ferro, e coloração branca. É um material formado por silicato de alumínio hidratado, cuja composição química aproxima-se de $\mathrm{Al}_{2} \mathrm{Si}_{2} \mathrm{O}_{5}(\mathrm{OH})_{4}$, que corresponde a $46,54 \% \mathrm{SiO}_{2}, 39,50 \% \mathrm{Al}_{2} \mathrm{O}_{3}, 13,96 \% \mathrm{H}_{2} \mathrm{O}$ sob a forma de hidroxila, e outros elementos em menor quantidade como ferro, titânio, manganês, magnésio, potássio e sódio [2]. No caso do beneficiamento de caulim, dois tipos de rejeitos são gerados: o primeiro é basicamente constituído de quartzo, proveniente da etapa de desareiamento (cerca de $10 \%$ ); já no segundo tipo, a quantidade resultante é maior correspondendo a aproximadamente $26 \%$ da produção bruta, sendo esse rejeito originado nas etapas de separação por centrifugação, separação magnética, branqueamento e filtragem, o qual é armazenado em grandes lagoas de sedimentação. Esse resíduo é constituído essencialmente pelo argilomineral caulinita, com granulometria e alvura inadequada para utilização em cobertura de papel, caracterizando-se dessa maneira em um material com grande potencial para ser empregado como matéria prima em vários processos e para diferentes tipos de aplicações [3-5]. Atualmente esse rejeito fora da especificação para a cobertura de papel tem como principais aplicações industriais em material de enchimento (filler) no preparo de papel e na composição das pastas cerâmicas. Em menor escala, o caulim é usado na fabricação de materiais refratários, plásticos, borrachas, tintas, adesivos, cimentos, inseticidas, pesticidas, produtos alimentares e farmacêuticos, catalisadores, absorventes, dentifrícios etc [2].

As zeólitas são definidas como aluminossilicatos hidratados de metais alcalinos ou alcalinos terrosos (principalmente sódio, potássio, magnésio e cálcio), com estruturas do tipo $\mathrm{TO}_{4}(\mathrm{~T}=\mathrm{Si}, \mathrm{Al}, \mathrm{B}, \mathrm{Ge}, \mathrm{Fe}, \mathrm{P}, \mathrm{Co} . .$.$) ,$ nos quais os tetraedros de silício e alumínio são unidos pelos vértices através do átomo de oxigênio [6,7]. Outra característica importante das zeólitas é que se constituem em materiais cristalinos que apresentam distribuição de poros e canais bem definidas e uniformes, diferenciandose dos materiais adsorventes comuns como as aluminas, carvão ativo e a sílica gel, que são amorfos e apresentam poros com diâmetros variáveis. Como mencionado, uma das principais características das zeólitas é a uniformidade do tamanho de seus poros que possibilita sua utilização como um adsorvente ou catalisador que apresentam alta seletividade $[7,8]$. O nome analcima deriva da palavra grega significando "fraco" por possuir fraca propriedade elétrica quando aquecida ou friccionada. Sua composição química é $\mathrm{NaAlSi}_{2} \mathrm{O}_{6} \mathrm{H}_{2}$. A estrutura contém canais abertos, permitindo assim o fluxo livre de moléculas de água e íons, podendo ser usada como peneira molecular. Um dos objetivos do trabalho é a produção da zeólita analcima pela utilização do rejeito caulim fora da especificação para cobertura de papel. Os processos de produção de zeólita normalmente utilizam excesso de hidróxido de sódio o qual no final do tempo de reação devem ser separado do meio através de filtração. Esse excesso é normalmente descartado do processo de síntese e constitui-se em problema econômico e ambiental, assim um segundo objetivo é o da modificação do processo desenvolvido [9], acrescida de uma etapa de recuperação da solução de $\mathrm{NaOH}$ descartada na metodologia anterior, por meio de um reciclo dessa solução. Como objetivo final este trabalho propõem o desenvolvimento de um processo de síntese de analcima em cinco ciclos consecutivos, de modo a reaproveitar o excesso de hidróxido de sódio descrito acima, para evitar o desperdício e o problema ambiental.

\section{MATERIAIS E MÉTODOS}

Materiais de partida: como fonte de silício e alumínio foi utilizado um subproduto de beneficiamento de caulim de baixo valor comercial, denominado Tube Press, produzido pela Imerys Rio Capim Caulim S/A-IRCC, Barcarena, Pará. $\mathrm{O}$ produto foi submetido a um processo de calcinação, em cadinhos de porcelana, em um forno mufla a $700{ }^{\circ} \mathrm{C}$ por $2 \mathrm{~h}$ no patamar de queima para a completa desidroxilação do material. A analcima possui uma relação $\mathrm{Si} / \mathrm{Al}>1$, sendo assim necessária uma fonte complementar de sílica. Para isso foi utilizado o diatomito "Terra Infusórios ou Terra Diatomácea”, Reagen Quimibrás Ind. Quim. S.A.. A fonte de metal alcalino usado na síntese foi hidróxido de sódio em solução aquosa 5 molar.

Processo de síntese: o processo de síntese ocorreu por meio de duas etapas, a primeira constituída do processo

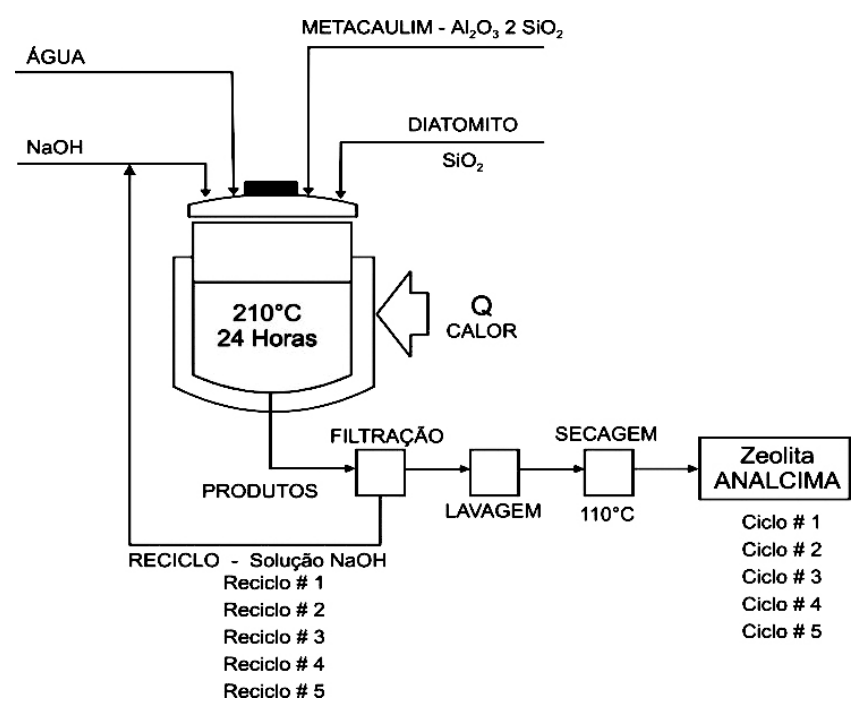

Figura 1: Fluxograma esquemático do processo de produção da zeólita analcima desenvolvido com recuperação de solução de hidróxido de sódio.

[Figure 1: Schematic flowchart of the production process developed with the zeolite analcime recovery solution of sodium hydroxide.] 
de calcinação do caulim em mufla a $700{ }^{\circ} \mathrm{C}$ por $2 \mathrm{~h}$ para promover a desidroxilação do caulim, transformando-o em metacaulim; a segunda etapa foi a de autoclavagem, na qual se adicionou o metacaulim, diatomito, solução de $\mathrm{NaOH} 5$ molar e água para que a mistura reacional apresentasse uma relação $\mathrm{Si} / \mathrm{Al}=7,2$, e $0,02 \mathrm{~mol}$ de $\mathrm{NaOH}$. O processo foi feito em uma autoclave de aço inox em uma mufla a $210{ }^{\circ} \mathrm{C}$ por 24 h. Após o período de reação e resfriamento da autoclave, a mistura reagente foi filtrada para separação da zeólita a qual foi submetida à lavagem com água destilada até $\mathrm{pH}=7$. A solução límpida de $\mathrm{NaOH}$ utilizada em excesso, separada na etapa de filtração, foi então reutilizada em um novo ciclo, de modo a complementar a solução de hidróxido de sódio utilizado no próximo ciclo de acordo com o fluxograma da Fig. 1. O processo desenvolvido foi realizado em triplicata com cinco ciclos consecutivos. A nomenclatura utilizada para as zeólitas obtidas nos ciclos do processo foi ANA-01 para o material obtido no primeiro ciclo, ANA-02, ANA-03, ANA-04 e ANA-05 para os ciclos consecutivos.

Análise térmica: a análise foi realizada em um equipamento PL Thermal Sciences, com cadinho de alumina e $10 \mathrm{mg}$ de amostra. A varredura iniciando na faixa de temperatura da ambiente até $1000{ }^{\circ} \mathrm{C}$, com taxa de aquecimento $20^{\circ} \mathrm{C} / \mathrm{mim}$.

Difração de raios $X$ : as análises foram em difratômetro de raios X X'Pert-X, (radiação k $\alpha 1=1,540598 \AA$ ), modelo PW3373/00, com filtro $k \beta$ de Ni. O detector utilizado foi X'Celeratoro RTMS no modo Scanning e com um active length de $2,122^{\circ}$, nas seguintes condições: varredura de $5^{\circ}$ a $75^{\circ} 2 \theta, 40 \mathrm{kV}, 40 \mathrm{~mA}$, passo $0,02^{\circ} 2 \theta$ e tempo/passo $5 \mathrm{~s}$, fenda divergente de $1 / 2^{\circ}$ e anti-espalhamento de $1^{\circ}$, máscara de $10 \mathrm{~mm}$, movimento da amostra: spinning $1 \mathrm{rps}$.
Fluorescência de raios $X$ : foram realizadas no programa IQ+ Semiquant, por FRX em pastilha fundida para elementos maiores e traços, utilizando o espectrômetro seqüencial Axios Minerals, tubo de raios X Rh, PANalytical. A preparação do disco de vidro foi com $1 \mathrm{~g}$ de amostra para $8 \mathrm{~g}$ de tetraborato de lítio; na pastilha prensada foram utilizadas $3 \mathrm{~g}$ de amostra para $0,6 \mathrm{~g}$ de parafina.

Microscopia eletrônica de varredura: as amostras foram montadas em suportes de alumínio com $10 \mathrm{~mm}$ de diâmetro com fita adesiva de carbono. Foram realizadas em um microscópio LEO 1450VP. A metalização foi feita a partir da interação entre um alvo de ouro e íons de argônio, a 2.10-1 mbar, e corrente de $25 \mathrm{~mA}$ durante $2,5 \mathrm{~min}$. As imagens foram geradas por detecção de elétrons secundários, com $20 \mathrm{kV}$.

\section{RESULTADOS E DISCUSSÃO}

Os resultados da análise química do caulim Tube Press, da composição teórica da caulinita, do diatomito Celite 545 utilizado e da zeólita analcima sintetizada neste trabalho, são apresentados na Tabela I. Para o caulim Tube Press, pode ser verificado que resultados dos teores de $\mathrm{SiO}_{2}$ de $46,7 \%, \mathrm{Al}_{2} \mathrm{O}_{3}$ igual a $38 \%$ e perda ao fogo (14\%) estão muito próximos do teórico apresentado pela caulinita, indicando que esse material é essencialmente constituído pelo argilomineral caulinita acompanhado por apenas $1,3 \%$ de impurezas, ou seja, trata-se de uma elevada pureza excelente fonte de sílica e alumina em qualquer processo de síntese de zeólitas. Os resultados da composição química da amostra Celite 545 mostram que este material apresenta também boa pureza para o processo a que se destina, sendo composto por $90,2 \%$ de

Tabela I - Análise química do caulim Tube Press e do diatomito Celite 545 e da zeólita analcima sintetizada.

[Table I - Chemical analysis of kaolin Tube Press and diatomite Celite 545 and the zeolite analcime synthesized.]

\begin{tabular}{cccccc}
\hline Óxidos (\%) & $\begin{array}{c}\text { Caulim } \\
\text { Tube Press }\end{array}$ & $\begin{array}{c}\text { Diatomito } \\
\text { Celite 545 }\end{array}$ & $\begin{array}{c}\text { Caulinita } \\
\text { teórico }\end{array}$ & $\begin{array}{c}\text { Zeólita } \\
\text { Analcima }\end{array}$ & $\begin{array}{c}\text { Analcima } \\
\text { teórico }\end{array}$ \\
\hline $\mathrm{SiO}_{2}$ & 46,71 & 90,17 & 46,71 & 64,53 & 59,40 \\
$\mathrm{Al}_{2} \mathrm{O}_{3}$ & 37,99 & 3,31 & 39,9 & 22,64 & 25,25 \\
$\mathrm{Fe}_{2} \mathrm{O}_{3}$ & 0,53 & 1,12 & - & 1,17 & - \\
$\mathrm{TiO}_{2}$ & 0,27 & 0,19 & - & 0,13 & - \\
$\mathrm{CaO}$ & 0,02 & 0,33 & - & 0,14 & - \\
$\mathrm{MgO}$ & - & 0,24 & - & - & - \\
$\mathrm{Na}$ & 0,22 & 4,13 & - & 14,56 & 15,35 \\
$\mathrm{~K}_{2} \mathrm{O}$ & 0,06 & 0,20 & - & 0,06 & - \\
$\mathrm{BaO}$ & 0,11 & - & - & - & - \\
$\mathrm{CuO}$ & - & - & - & - & - \\
$\mathrm{ZrO}$ & 0,01 & - & - & - & - \\
$\mathrm{P}_{2} \mathrm{O}_{5}$ & 0,02 & 0,03 & - & 0,03 & - \\
$\mathrm{PF}^{2}$ & 13,98 & 0,20 & 13,98 & - & - \\
\hline$P F=$
\end{tabular}




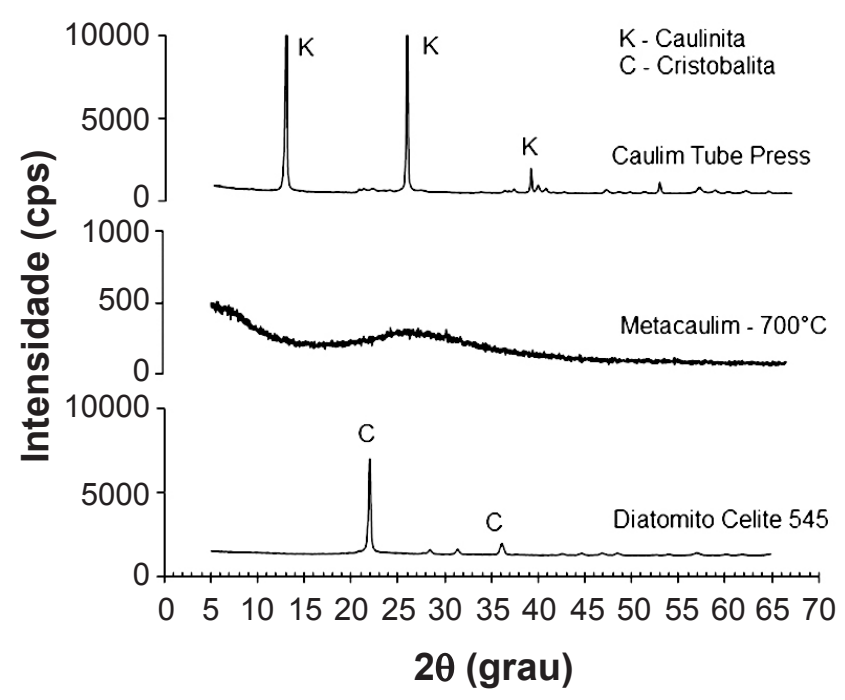

Figura 2: Difratogramas de raios X do caulim Tube Press, do metacaulim e do diatomito Celite 545.

[Figure 2: XRD patterns of the Tube Press kaolin, metakaolin and diatomite Celite 545.]

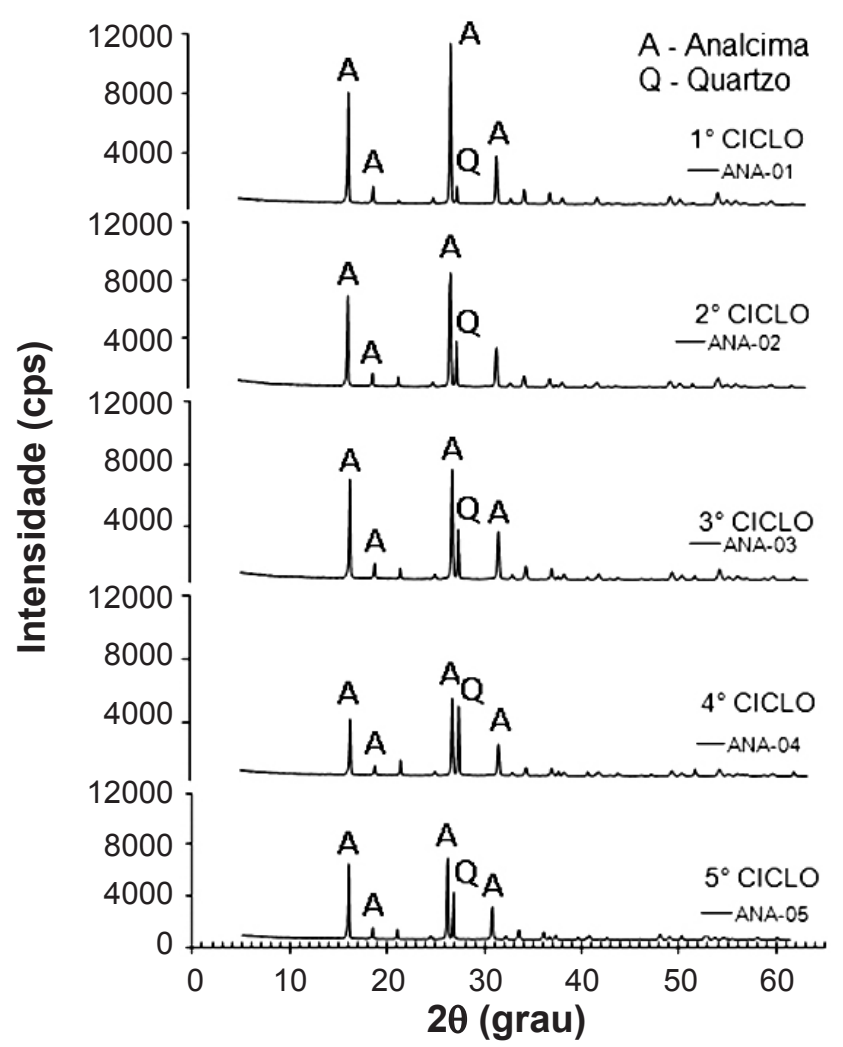

Figura 3: Difratogramas de raios $\mathrm{X}$ das zeólitas analcimas sintetizadas nos cinco ciclos do processo.

[Figure 3: XRD patterns of zeolites analcime synthesized in five cycles of the process.]

$\mathrm{SiO}_{2}$, acompanhado por $3,3 \%$ de $\mathrm{Al}_{2} \mathrm{O}_{3}$ e $4,1 \% \mathrm{Na}_{2} \mathrm{O}$ como contaminantes principais, o que não afeta sua utilização na síntese de zeólitas. Analisando a composição química média das zeólitas analcima sintetizada nos diferentes ciclos, pode ser verificado que os resultados são próximos
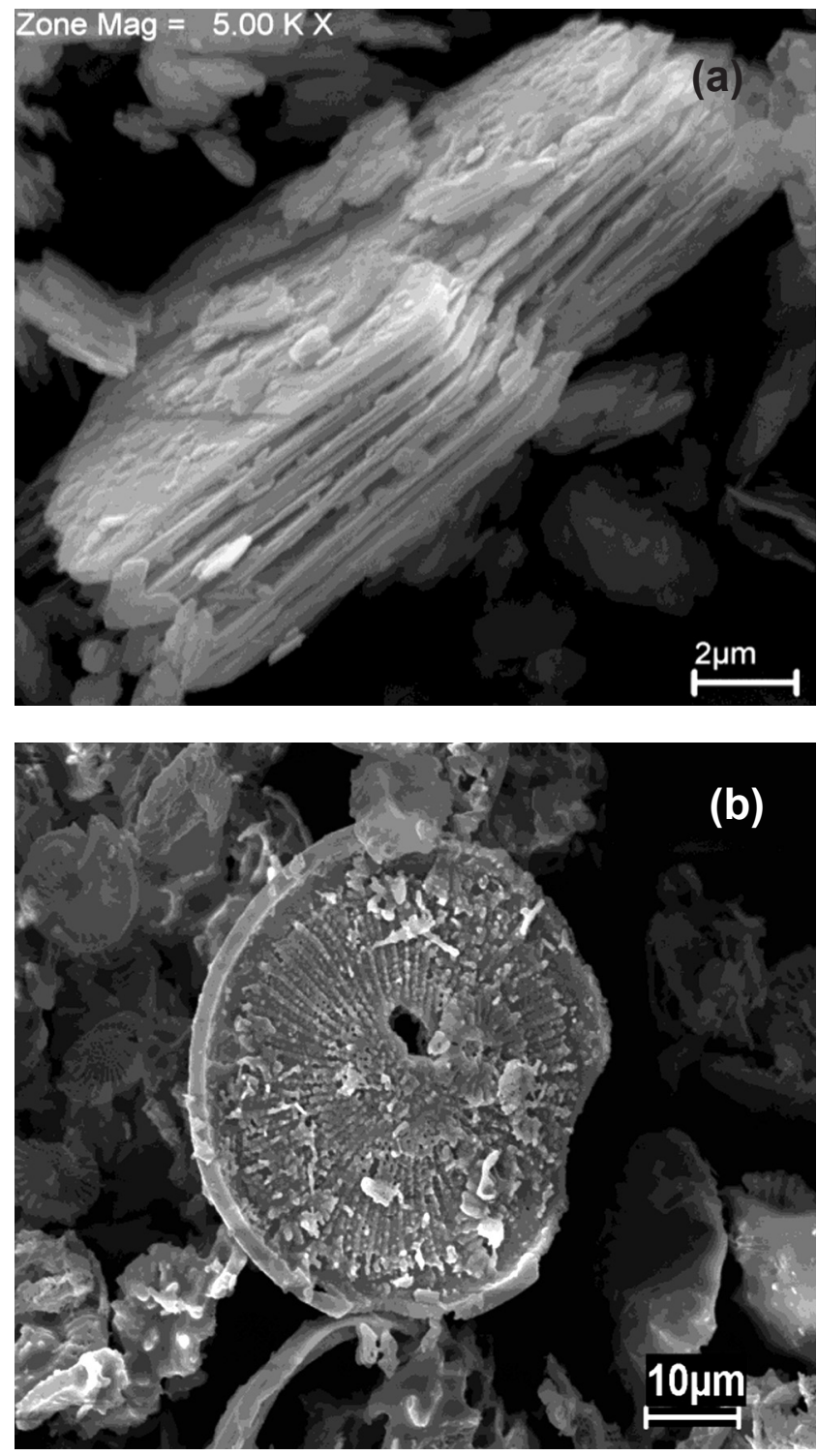

Figura 4: Micrografias obtidas por microscopia eletrônica de varredura do caulim Tube Press e do diatomito Celite, utilizados na síntese das zeólitas analcima sintetizadas nos diferentes ciclos do processo.

[Figure 4: Scanning electron microscopy micrographs of kaolin Tube Press and the Celite diatomaceous earth, used in the synthesis of analcime zeolites synthesized in the different cycles of the process.]

dos valores teóricos da estrutura da analcima, levamos em consideração as baixas impurezas introduzidas com o diatomito e com o caulim.

Os resultados das análises de DRX do caulim Tube Press, do metacaulim, e do diatomito Celite 545 são apresentados na Fig. 2, e das zeólitas analcimas obtidas em cada ciclo na Fig. 3. O difratograma do caulim mostra que constitui-se essencialmente do argilomineral caulinita com a presença do pico de quartzo de muito baixa intensidade. O difratograma de raios $\mathrm{X}$ do diatomito Celite 545, que teoricamente seria não cristalino, apresentou picos característicos de cristobalita, que pode ter sido formada 


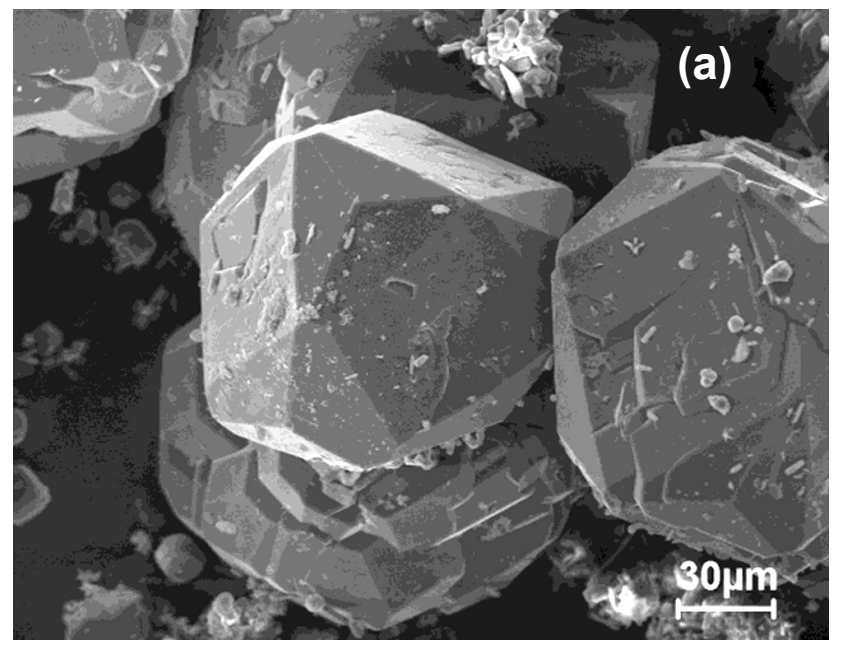

Primeiro Ciclo

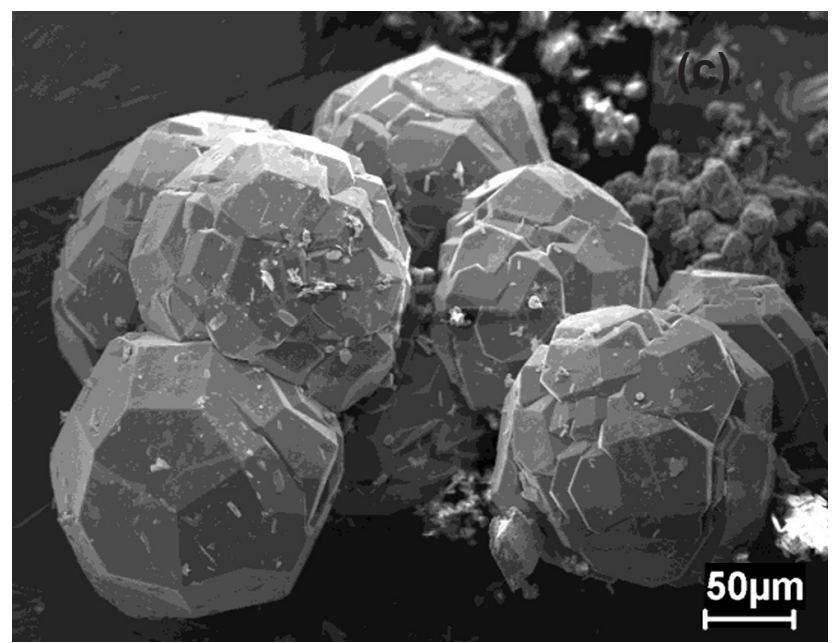

Segundo Ciclo

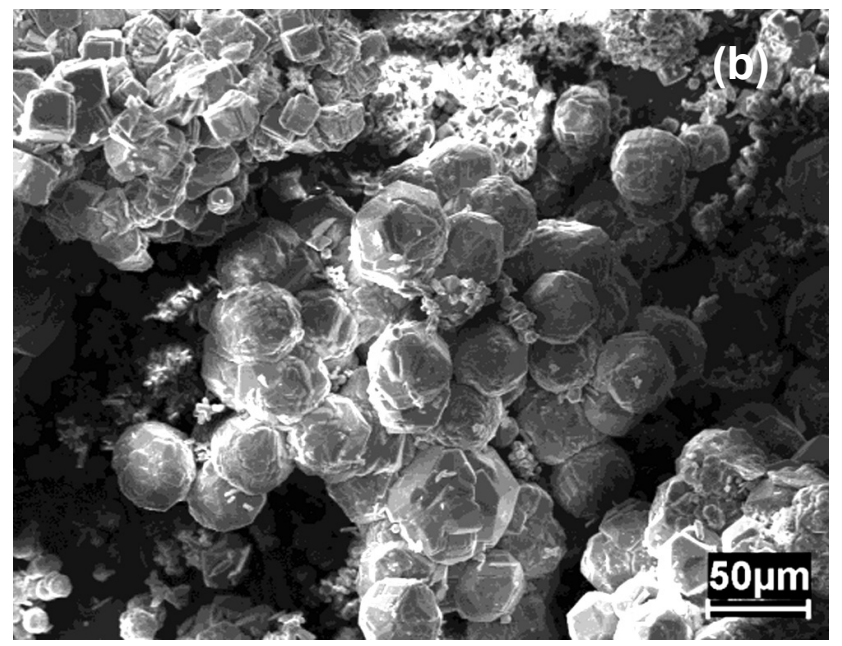

Primeiro Ciclo

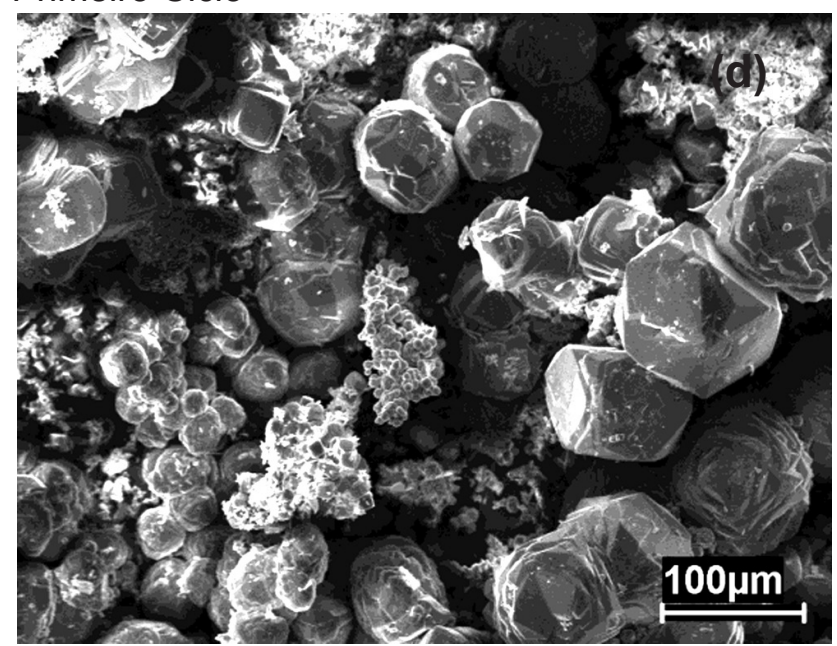

Segundo Ciclo

Figura 5: Micrografias obtidas por microscopia eletrônica de varredura das zeólitas analcima sintetizadas no primeiro e no segundo ciclo do processo.

[Figure 5: Scanning electron microscopy micrographs of analcime zeolites synthesized in the first and second cycle of the process.]

durante a calcinação no processo de produção industrial. $\mathrm{O}$ metacaulim produzido a $700{ }^{\circ} \mathrm{C} / 2 \mathrm{~h}$ apresentou-se totalmente amorfo. Os resultados das análises de todos os difratogramas dos produtos sintetizado nos cinco ciclos foram semelhantes, isto é, a analcima foi identificada como fase cristalina predominante em todos os ciclos, estando presentes picos de quartzo de baixa intensidade.

As imagens de microscopia eletrônica de varredura dos materiais de partidas e das zeólitas sintetizadas no trabalho são mostradas nas Figs. 4, 5 e 6. De um modo geral, a morfologia que os cristais de analcima apresentaram em todos os ciclos é de forma trapezoédrica entalhada, esférica e na forma cúbicos bem formados, característicos da zeólita analcima. Foram observados também cristais de quartzo, confirmando os resultados de DRX.

A análise térmica diferencial e termogravimétrica do caulim Tube Press e das analcimas sintetizadas nos diferentes ciclos são apresentadas nas Figs. 7 e 8 , respectivamente. A análise térmica diferencial do caulim apresenta um pico endotérmico com seu máximo em
$540{ }^{\circ} \mathrm{C}$, referente ao rompimento da estrutura cristalina pela reação de desidroxilação e um pico exotérmico em $\sim 980{ }^{\circ} \mathrm{C}$ referente à cristalização de mullita ou de um espinélio alumínio-silício [2, 10-12] característico da caulinita; na curva temogravimétrica observa-se apenas uma perda de massa a $540{ }^{\circ} \mathrm{C}$ de $\sim 13,5 \%$, referente à perda de hidroxilas sob a forma de vapor referente à desidroxilação, valor este muito próximo ao valor teórico da caulinita que é de $13,98 \%$. A análise do ATD da zeólita analcima apresentou uma banda endotérmica de baixa intensidade em $210{ }^{\circ} \mathrm{C}$, um pico endotérmico de alta intensidade em $\sim 360^{\circ} \mathrm{C}$ e outra banda de média intensidade em $650^{\circ} \mathrm{C}$. A temperaturas mais altas observase uma transformação endotérmica contínua do material, que se prolonga até a temperatura de $1100{ }^{\circ} \mathrm{C}$. Por meio da curva termogravimétrica foi observada uma perda de massa de $8 \%$ que ocorre na faixa de $100{ }^{\circ} \mathrm{C}$ a $360{ }^{\circ} \mathrm{C}$. Essa extensa faixa de temperatura para a perda de água é característica dos materiais que apresentam poros e canais de baixas dimensões como as zeólitas [2]. 

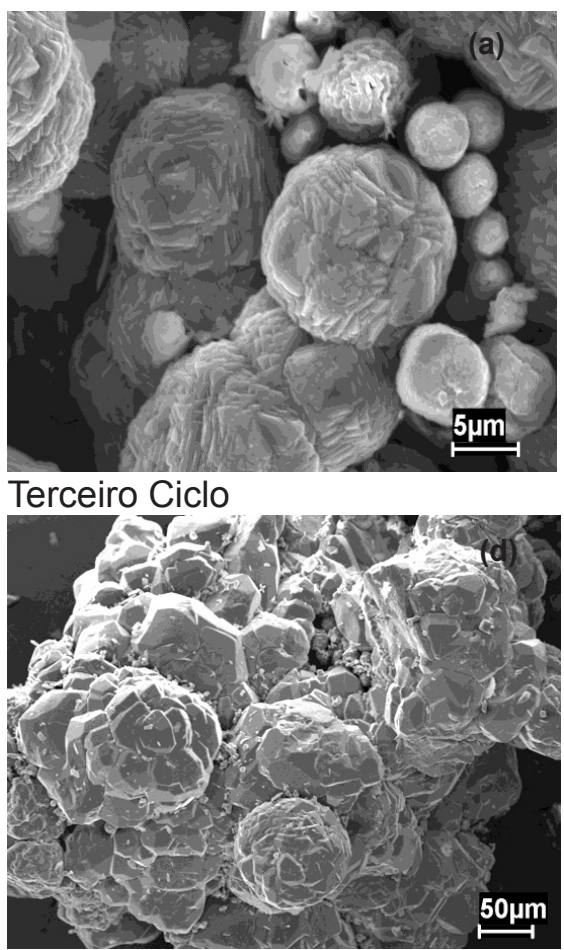

Quarto Ciclo

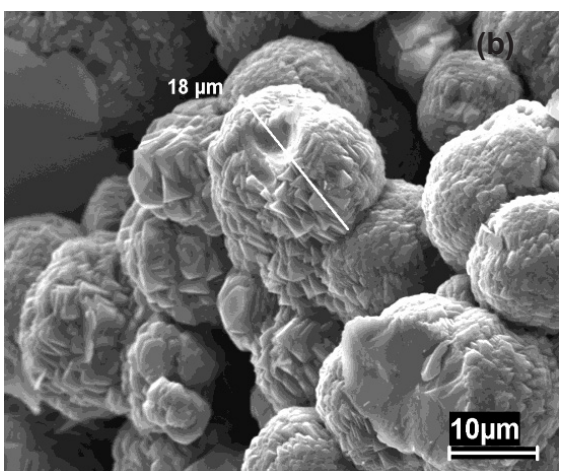

Terceiro Ciclo

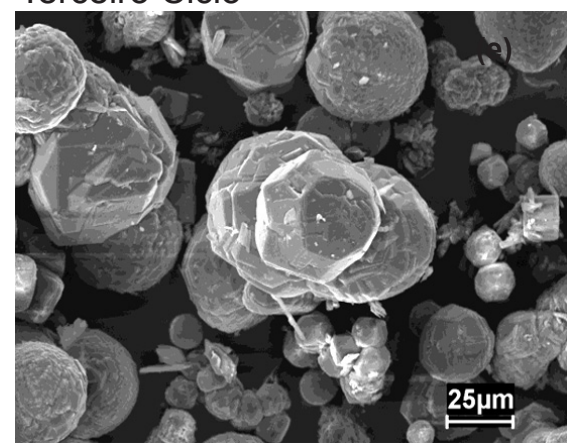

Quinto Ciclo

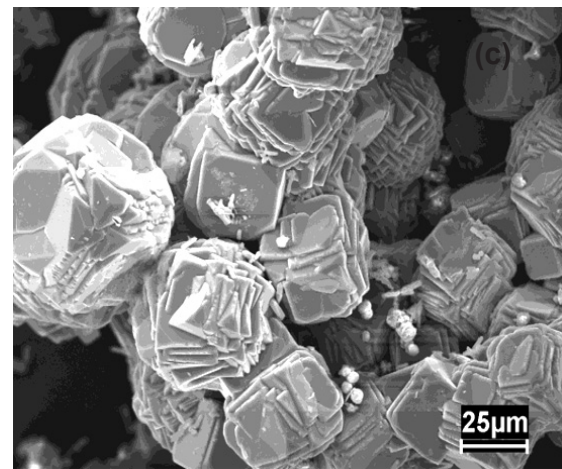

Quarto Ciclo

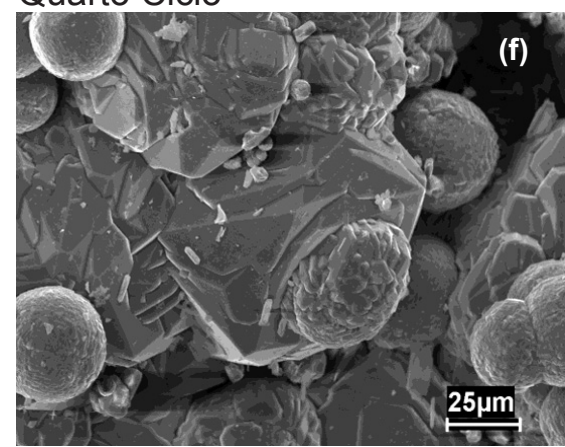

Quinto Ciclo

Figura 6: Micrografias obtidas por microscopia eletrônica de varredura das zeólitas analcima sintetizadas no terceiro, quarto e quinto ciclo do processo.

[Figure 6: Scanning electron microscopy of analcime zeolites synthesized in the third, fourth and fifth cycle of the process.]

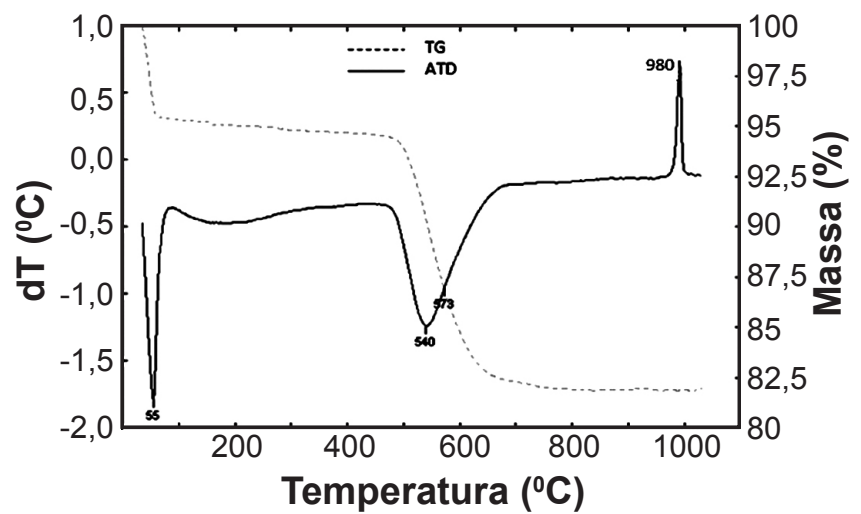

Figura 7: Curvas de análise térmica diferencial e termogravimétrica do caulim Tube Press.

[Figure 7: Differential thermal analysis and thermogravimetric curves of Tube Press kaolin.]

\section{CONCLUSÕES}

Pela utilização do caulim Tube Press foi possível produzir a zeólita analcima como fase cristalina predominante em todos os cinco ciclos do processo, como pode ser constatado nos difratogramas de raios $\mathrm{X}$. A reutilização da solução de $\mathrm{NaOH}$ em excesso, necessária normalmente nas sínteses de zeólitas , mostrou-se plenamente viável, visto que em todos os ciclos obteve-se como fase cristalina predominante a analcima, acompanhada de quartzo em baixas concentrações. A recuperação do hidróxido de sódio utilizado em excesso e

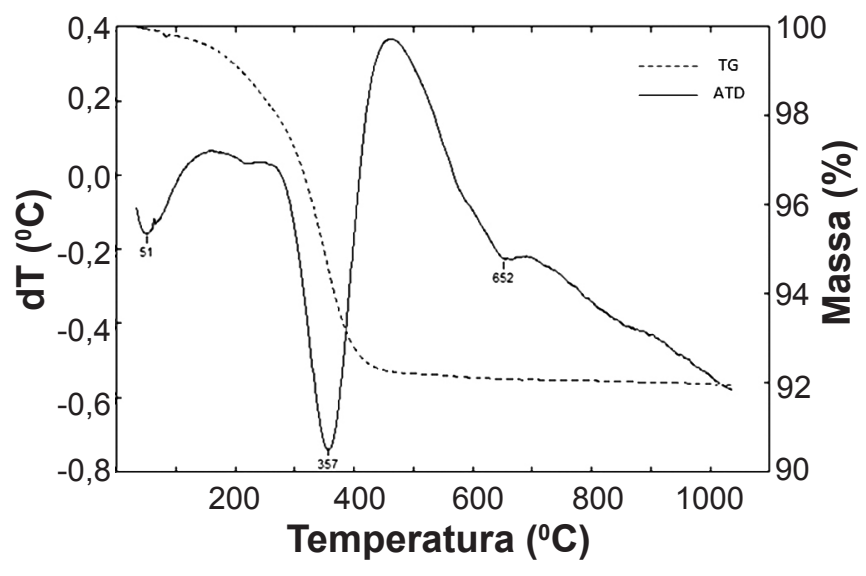

Figura 8: Curvas de análise térmica diferencial e termogravimétrica da zeólita analcima.

[Figure 8: Differential thermal analysis and thermogravimetric curves of zeolite analcime.]

recuperado através de reciclo possibilitou a economia de $31 \%$ no consumo de hidróxido de sódio que seria desperdiçado normalmente, em cada ciclo se não houvesse o reciclo. A aplicação do reciclo da solução de hidróxido de sódio no processo de síntese de analcima não exerceu modificações significativas ou marcantes no que se refere à morfologia dos cristais produzidos nos diferentes ciclos. Os cristais obtidos em todos os ciclos apresentaram as formas trapezoédrica entalhada e cúbica. A viabilidade da reutilização do hidróxido de sódio pelo processo de reciclo também vem minimizar o 
problema sério de impacto ambiental devido ao seu descarte, fator esse não descrito na literatura e não mencionado como possibilidade da reutilização.

\section{REFERÊNCIAS}

[1] DNPM - Departamento Nacional de Produção Mineral, Sumário Mineral (2008), http://www.dnpm.gov.br/, acessado em 15/05/2009.

[2] P. S. Santos, "Ciência e Tecnologia de Argilas", 2a Ed., Ed. Blucher, S. Paulo, SP (1989) v.1.

[3] M. S. Barata, Concreto de Alto Desempenho no Pará: Estudo da viabilidade Técnica e Econômica de produção de concreto de alto desempenho com os materiais disponíveis em Belém através do emprego de adições de sílica ativa e metacaulim, Diss. Mestrado, Programa de Pós-Graduação em Eng. Civil, Universidade Federal do Rio Grande do Sul, Porto Alegre, RS (1998) 164 f.; S. M. P. Flores, Aproveitamento do rejeito de caulim na produção de Alumina para Cerâmica e Sílica de baixa granulometria, Tese Dr. Geoquímica e Petrologia, Instituto de Geociências, Universidade Federal do Pará, Belém, PA (2000).
[4] M. C. Martinelli, Transformações Térmicas e Propriedades Cerâmicas de Resíduos de Caulins das Regiões do Rio Capim e do Rio Jarí - Brasil, Tese Dr. Geoquímica e Petrologia, Centro de Geociências, Universidade Federal do Pará, Belém, PA (2006).

[5] R. M. Barrer, "Zeolites and Clay Minerals as Sorbents and Molecular Sieves", Academic Press, EUA (1978).

[6] D. B. Breck, "Zeolitic Molecular Sieves: structure, chemistry, and use", Wiley-Intersci., EUA (1973).

[7] A. B. Luz, "Zeólitas: Propriedades e Usos industriais", Série Tecnologia Mineral, Rio de Janeiro, RJ, n. 68 (1994).

[8] E. Saldanha, Sintese e caracterização da Zeólita Analcima a partir de rejeito de caulim e aplicação como adsorvente, Diss. Mestrado Engenharia Química, Instituto de Tecnologia, Universidade Federal do Pará, Belém, PA (2006).

[9] G. W. Brindley, M. Nakahira, J. Am. Ceram. Soc. 42, 7 (1959) 311-314.

[10] G. W. Brindley, M. Nakahira, J. Am. Ceram. Soc. 42, 7 (1959) 314-318.

[11] G. W. Brindley, M. Nakahira, J. Am. Ceram. Soc. 42, 7 (1959) 319-324.

(Rec. 20/08/2012, Ac. 18/05/2013) 


\section{Errata}

Cerâmica 56, 340 (2010) 315-319

Adaptação de um equipamento para ensaios de desgaste de materiais cerâmicos (Experimental setup for wear testing of ceramic materials)

R. F. de L. Lorenzi, C. A. Perottoni, J. E. Zorzi

A equação (B) da página 317 é:

$$
g\left(\mathrm{~m} / \mathrm{s}^{2}\right)=9,780356\left(1+0,0052885 \operatorname{sen}^{2} \theta-0,0000059 \operatorname{sen}^{2} 2 \theta\right)-0,003086 H
$$

na qual $g$ é a aceleração da gravidade, $H$ é a altitude $(\mathrm{em} \mathrm{km})$ e $\theta$ é a latitude [11]. A aceleração da gravidade calculada para Caxias do Sul é $9,789 \mathrm{~m} / \mathrm{s}^{2}$.

Cerâmica 59, 352 (2013) 563-569

O título correto do artigo é:

Produção de zeólita analcima a partir de caulim amazônico

(Analcime zeolite production from amazon kaolin)

C. G. Moraes, E. C. Rodrigues, R. S. Angélica, E. N. Macêdo, R. F. Neves 